\title{
ÍNDICE DE TEMPERATURA E UMIDADE (ITU) NA PRODUÇÃO DE AVES PARA MESORREGIÃO DO NOROESTE E NORTE PIONEIRO PARANAENSE
}

\author{
Temperature Humidity Index (ITU) in Poultry Production at \\ Northwest and North Regions of Parana State
}

Eduardo Teixeira da Silva

Engenheiro Agrícola, Dr., Prof. da UFPR, Curitiba - PR. e-mail: eduardo@ufpr.br

\section{Resumo}

O objetivo do presente trabalho foi determinar o Índice de Temperatura e Umidade (ITU) para a produção de aves na mesorregião Noroeste e Norte Pioneiro do Paraná, como orientação a avicultores e futuros avicultores na implantação de sistemas de controle ambiental. A determinação do ITU foi realizada com os dados climáticos fornecidos pelo "IAPAR normais climatológicas" das seguintes microrregiões: Paranavaí e Umuarama, e Bandeirantes. Os valores da Temperatura Média do Ar Compensada, Umidade Relativa e ITU foram utilizados para comparar com as condições de conforto térmico para aves, em função da idade. As comparações realizadas em cada microrregião mostraram a necessidade de corrigir o microclima dos galpões para alcançar condições ideais para produção de aves.

Palavras-chave: Conforto térmico; Índice de temperatura e umidade; Avicultura.

\begin{abstract}
It was objective of this paper to determinate the Temperature and Humidity Index (ITU) for the bird production in the Northwest and North of the Parana State, as orientation to the poultry keepers and futures poultry keepers in the establishment of environmental control systems. The ITU determination was carried through with the climatic data supplied by the "IAPAR climatologic normal" of the following microrregions: Paranavai and Umuarama, and Bandeirantes. The values of the Average Temperature of Compensated Air, Relative Humidity and ITU had been used to compare with the specified conditions of thermal comfort for birds, in function of the age. The comparisons carried through in each microrregion had shown the necessity to correct the microclimate of the sheds to reach ideal conditions for poultry production.
\end{abstract}

Keywords: Thermal comfort; Index of temperature and humidity; Poultry. 


\section{INTRODUÇÃO}

A avicultura brasileira registrou nos últimos anos aumentos significativos na produção de carne. As exportações de carne de frango em agosto, considerando também os industrializados, foram de 299.151 toneladas, novo recorde na história do setor. A ABEF confirmou que 95,5\% do volume embarcado no mês (285.745 toneladas) foi de carne de frango in natura que, portanto, registrou aumento de $11,76 \%$ em relação a agosto de 2005 e de 60,31\% em relação a julho de 2005 . Nos dois terços iniciais do ano de 2006 as exportações brasileiras de carne de frango in natura somaram 1,649 milhão de toneladas, permanecendo 9,74\% inferiores às do mesmo período de 2005. Projetado para o terço faltante de 2006, esse volume sugere embarques totais da ordem de 2,470 milhões de toneladas, 10,5\% a menos que o exportado no decorrer de 2005. Entretanto, eram claros os indícios de um índice de redução menor. Assim, por exemplo, mantido o desempenho registrado nos dois primeiros meses daquele semestre (média mensal de 232 mil toneladas no bimestre julho-agosto), as exportações de carne de frango in natura iriam ficar próximas dos 2,580 milhões de toneladas, volume 6,6\% inferior ao do ano de 2005. De setembro de 2005 a agosto de 2006, o volume exportado totalizou 2,583 milhões de toneladas, volume que representou decréscimo de 3,67\% sobre o total exportado nos doze meses imediatamente anteriores, o que mantém o Brasil como o segundo maior produtor mundial. Contudo, em muitas regiões brasileiras, a radiação solar intensa conduz a altos valores de temperatura do ar, principalmente no verão, gerando condições de desconforto térmico ao bom desempenho avícola, nas suas variadas formas de exploração. Acrescentese a isso, segundo Garcia (2004), o fato de o país ser um grande produtor de soja e milho - principais componentes da ração alimentar para frangos de corte - e a implantação de sistema de produção em "parceria avícola", nos principais estados produtores. Segundo Fernandes Filho e Queiroz (2001), o desempenho da avicultura de corte foi significativamente melhor do que o observado para a produção de outros tipos de carnes no Brasil, como as de suínos e da tradicional carne de bovinos, o que fez com que o setor ganhasse importância social e econômica no país.

O mecanismo de homeostase, entretanto, é eficiente somente quando a temperatura dos ambientes está dentro de certos limites, segundo Ticôno (1998). Portanto, é importante que as instalações sejam mantidas a temperaturas ambientais próximas às das condições de conforto. Outro fator importante e que interage juntamente com a temperatura é a umidade relativa do ar. A umidade relativa em ambientes é limitante para a maioria dos homeotermos adultos, quando a temperatura supera a marca dos $24^{\circ} \mathrm{C}$ e mais pronunciadamente quando ultrapassa o valor de $30^{\circ} \mathrm{C}$. A umidade relativa passa a ter importância no conforto térmico das aves, quando a temperatura ambiental atinge $25^{\circ} \mathrm{C}$. Altas taxas de umidade relativa, associadas às temperaturas altas, fazem com que menos umidade seja removida das vias aéreas, tornando a respiração cada vez mais ofegante, segundo Tinoco (1998). Assim, a inter-relação entre as características climáticas regionais com as exigências bioclimáticas das aves será de grande importância no melhoramento e aumento do rendimento da produção de monogástricos na mesorregião.

Portanto, construir instalações adequadas ao clima e que permitam a manutenção de temperatura, umidade relativa, velocidade do ar, em limites que proporcionam ambiente ideal no interior do galpão de acordo com as exigências das aves, sem aumento dos custos de produção, tem sido grande desafio. O objetivo deste trabalho foi determinar o Índice de Temperatura e Umidade (ITU) para a produção de aves na mesorregião Noroeste e Norte Pioneiro do Paraná, como orientação aos avicultores e futuros avicultores na implantação de sistemas de controle ambiental.

\section{MATERIAIS E MÉTODOS}

O Estado do Paraná localiza-se na Região Sul do País, ocupando uma área de $199.725 \mathrm{~km}^{2}$, que corresponde a 2,3\% da superfície total do Brasil, situando-se entre os meridianos de $48^{\circ} 30^{\prime}$ e $54^{\circ} 30^{\prime}$ de longitude a oeste de Greenwich e os paralelos de $22^{\circ} 30^{\prime}$ e $26^{\circ} 30^{\prime}$ de latitude sul. O Paraná está dividido em 10 mesorregiões, das quais foram utilizadas a Noroeste e o Norte Pioneiro, em que foram selecionadas três estações agrometeorológicas, duas na primeira e uma na segunda mesorregião, cobrindo as seguintes 
microrregiões: Paranavaí e Umuarama, e Bandeirantes, respectivamente. Na Tabela 1 está apresentada a caracterização das microrregiões. A determinação do ITU foi realizada com os dados climáticos obtidos das normais climatológicas fornecidos pelo Instituto Agronômico do Paraná - Área de Ecofisiologia (IAPAR).

TABELA 1 - Caracterização das microrregiões analisadas

Table 1 - Characterization of the analyzed microregions

\begin{tabular}{l|c|c|c|c|c|c}
\hline Microrregião & Longitude & Latitude & Altitude $(\mathrm{m})$ & Area $\left(\mathrm{km}^{2}\right)$ & Ano inicio & Ano fim \\
\hline Paranavaí & $52^{\circ} 26^{\prime \prime} \mathrm{W}$ & $23^{\circ} 5^{\prime \prime} \mathrm{S}$ & 480 & $1.190 .552,0$ & 1971 & 2004 \\
Umuarama & $53^{\circ} 17^{\prime \prime} \mathrm{W}$ & $23^{\circ} 44^{\prime \prime} \mathrm{S}$ & 480 & $1.375 .135,0$ & 1971 & 2004 \\
Bandeirantes & $50^{\circ} 21^{\prime \prime} \mathrm{W}$ & $23^{\circ} 6^{\prime \prime} \mathrm{S}$ & 440 & $467.534,0$ & 1974 & 2004 \\
\hline
\end{tabular}

Para o estudo, foram utilizadas as seguintes variáveis:

- média da Temperatura do Ar Compensada (temperatura média);

- umidade Relativa do Ar (UR); e

- índice de temperatura e Umidade (ITU).

O Índice de Temperatura e Umidade (ITU) foi determinado pela equação (01), desenvolvida por Thom (1958):

$$
\mathrm{ITU}=\mathrm{T}_{\mathrm{bs}}+0,36 \mathrm{~T}_{\mathrm{po}}-330,08
$$

Onde:

Tbs = temperatura de bulbo seco $(\mathrm{K})$

Tpo $=$ temperatura de ponto de orvalho $(K)$

Estes valores foram utilizados para comparar com as condições de conforto térmico ideais para aves, em função da sua idade em semanas de vida (TABELA 2). Para comparar as exigências das aves com os valores climáticos das microrregiões, foi adotada a seguinte simbologia:

I - Inferiores aos exigidos pelas aves;

C - confortáveis aos exigidos pelas aves e;

$\mathrm{S}$ - superiores aos exigidos pelas aves.

TABELA 2 - Valores ideais de temperatura, umidade relativa do ar e do índice de temperatura e umidade (ITU), em função da idade das aves

Table 2 - Ideal values of temperature, relative humidity of the air and the temperature and bumidity index (ITU), as function of the bird's age

\begin{tabular}{l|c|c|c}
\hline $\begin{array}{l}\text { Idade } \\
\text { (Semanas) }\end{array}$ & Temperatura (०C) & $\begin{array}{c}\text { Umidade Relativa do Ar } \\
(\%)\end{array}$ & ITU ideal \\
\hline 1 & $32-35$ & $60-70$ & $72,4-80$ \\
2 & $29-32$ & $60-70$ & $68,4-76$ \\
3 & $26-29$ & $60-70$ & $64,5-72$ \\
4 & $23-26$ & $60-70$ & $60,5-68$ \\
5 & $20-23$ & $60-70$ & $56,6-64$ \\
6 & 20 & $60-70$ & $56,6-60$ \\
7 & 20 & $60-70$ & $56,6-60$ \\
\hline
\end{tabular}

Fonte: ABREU; ABREU, 2001. 


\section{RESULTADOS E DISCUSSÃO}

\section{Município de Paranavaí}

Analisando as Tabelas do ITU (TABELAS 2 e 3), nos meses de janeiro a dezembro, referente ao ciclo de vida de aves de corte, verifica-se que para a primeira semana de vida das aves, durante os meses de dezembro a março, o ITU apresenta-se dentro da faixa considerada como confortável, portanto sem a necessidade da utilização de equipamentos que promovam aquecimento do microclima no galpão de criação, sendo necessário durante o restante do ano. O mesmo pode ser verificado para a $2^{a}$ semana de idade, porém agora se iniciando no mês de outubro e terminando em abril, ou seja, condições confortáveis neste período e necessidade de aquecimento durante o restante do ano. Durante a $3^{\text {a }}$ semana de idade, existe a necessidade de resfriamento do galpão durante os meses de dezembro a março, condições indesejável com necessidade de aquecimento no mês de julho, porém durante o restante do ano as condições são confortáveis. Durante a $4^{a}$ e $5^{a}$ semana de idade, as aves necessitam de um sistema de resfriamento do microclima galpão durante os meses de outubro a abril ( $4^{a}$ semana de idade) e apresenta-se confortável apenas durante o mês de julho para a $5^{\mathrm{a}}$ semana de idade. Já para a $6^{\mathrm{a}}$ e $7^{\mathrm{a}}$, o microclima gerado nos galpões são superiores aos exigidos pelas aves, necessitando de um eficiente sistema de resfriamento.

TABELA 3 - Índice de Temperatura e Umidade (ITU) para o município de Paranavaí Table 3 - Temperature and Humidity Index (ITU) for the municipality of Paranavai

\begin{tabular}{lc|c|c|c|c|c}
\hline \multirow{2}{*}{ Meses } & \multicolumn{7}{c}{ Idade em semanas de vida } \\
\cline { 2 - 7 } & $1^{\mathrm{a}}$ semana & $2^{\mathrm{a}}$ semana & $3^{\mathrm{a}}$ semana & $4^{\mathrm{a}}$ semana & $5^{\mathrm{a}}$ semana & $6^{\mathrm{a}}$ e $7^{\mathrm{a}}$ semanas \\
\hline Janeiro & $\mathrm{C}$ & $\mathrm{C}$ & $\mathrm{S}$ & $\mathrm{S}$ & $\mathrm{S}$ & $\mathrm{S}$ \\
Fevereiro & $\mathrm{C}$ & $\mathrm{C}$ & $\mathrm{S}$ & $\mathrm{S}$ & $\mathrm{S}$ & $\mathrm{S}$ \\
Março & $\mathrm{C}$ & $\mathrm{C}$ & $\mathrm{S}$ & $\mathrm{S}$ & $\mathrm{S}$ & $\mathrm{S}$ \\
Abril & $\mathrm{I}$ & $\mathrm{C}$ & $\mathrm{C}$ & $\mathrm{S}$ & $\mathrm{S}$ & $\mathrm{S}$ \\
Maio & $\mathrm{I}$ & $\mathrm{I}$ & $\mathrm{C}$ & $\mathrm{C}$ & $\mathrm{S}$ & $\mathrm{S}$ \\
Junho & $\mathrm{I}$ & $\mathrm{I}$ & $\mathrm{C}$ & $\mathrm{C}$ & $\mathrm{S}$ & $\mathrm{S}$ \\
Julho & $\mathrm{I}$ & $\mathrm{I}$ & $\mathrm{I}$ & $\mathrm{C}$ & $\mathrm{C}$ & $\mathrm{S}$ \\
Agosto & $\mathrm{I}$ & $\mathrm{I}$ & $\mathrm{C}$ & $\mathrm{C}$ & $\mathrm{S}$ & $\mathrm{S}$ \\
Setembro & $\mathrm{I}$ & $\mathrm{I}$ & $\mathrm{C}$ & $\mathrm{C}$ & $\mathrm{S}$ & $\mathrm{S}$ \\
Outubro & $\mathrm{I}$ & $\mathrm{C}$ & $\mathrm{C}$ & $\mathrm{S}$ & $\mathrm{S}$ & $\mathrm{S}$ \\
Novembro & $\mathrm{I}$ & $\mathrm{C}$ & $\mathrm{C}$ & $\mathrm{S}$ & $\mathrm{S}$ & $\mathrm{S}$ \\
Dezembro & $\mathrm{C}$ & $\mathrm{C}$ & $\mathrm{S}$ & $\mathrm{S}$ & $\mathrm{S}$ & $\mathrm{S}$ \\
\hline
\end{tabular}

\section{Município Umuarama}

Analisando-se as Tabelas do ITU (TABELAS 2 e 4) durante os meses de janeiro a dezembro, referente ao ciclo de vida de aves de corte, verifica-se que para a $1^{\text {a }}$ semana de idade, o microclima apresenta valores inferiores durante os meses de abril a novembro, necessitando de um sistema de aquecimento para as aves neste período, o que não ocorre durante o restante do ano nesta fase de vida das aves; para a $2^{a}$ semana de idade, pode-se verificar a mesma ocorrência, porém por um período menor, com necessidade de aquecimento, agora, durante os meses de maio a setembro. Para a $3^{a}$ semana de idade, pode-se verificar que apenas durante o mês de julho existe a necessidade de aquecimento do microclima, porém durante os meses de dezembro a março, tem-se o inverso, ou seja, a necessidade de resfriamento do galpão, apresentando-se dentro dos limites de conforto térmico durante os meses restantes para essa fase de vida das aves. Para a $4^{\mathrm{a}}$ semana, verifica-se que o ITU apresenta-se dentro dos limites de conforto térmico para as aves durante os meses de maio a setembro, mas ultrapassam os valores superiores, necessitando de resfriamento do microclima de outubro a abril. Para as $5^{\mathrm{a}}, 6^{\mathrm{a}}$ e $7^{\mathrm{a}}$ semanas de idade, pode-se verificar que o ITU apresenta 
valores superiores em praticamente todo o ano, gerando necessidade de resfriamento do microclima dentro do galpão, ou seja, os equipamentos de resfriamento da temperatura necessitam estar em funcionamento durante praticamente os 12 meses do ano, o que gera um aumento nos custos de produção.

TABELA 4 - Índice de Temperatura e Umidade (ITU) para o município de Umuarama

Table 4 - Temperature and humidity Index (ITU) for the municipality of Umuarama

\begin{tabular}{|c|c|c|c|c|c|c|}
\hline \multirow{2}{*}{ Meses } & \multicolumn{6}{|c|}{ Idade em semanas de vida } \\
\hline & $1^{a}$ semana & $2^{a}$ semana & $3^{a}$ semana & $4^{\mathrm{a}}$ semana & $5^{a}$ semana & $6^{a}$ e $7^{a}$ semanas \\
\hline Janeiro & $\mathrm{C}$ & $\mathrm{C}$ & S & S & S & S \\
\hline Fevereiro & $\mathrm{C}$ & $\mathrm{C}$ & S & $\mathrm{S}$ & S & $\mathrm{S}$ \\
\hline Março & $\mathrm{C}$ & $\mathrm{C}$ & S & S & S & S \\
\hline Abril & I & $\mathrm{C}$ & $\mathrm{C}$ & $\mathrm{S}$ & S & $\mathrm{S}$ \\
\hline Maio & I & I & $\mathrm{C}$ & $\mathrm{C}$ & S & S \\
\hline Junho & I & I & $\mathrm{C}$ & $\mathrm{C}$ & S & S \\
\hline Julho & I & I & I & $\mathrm{C}$ & C & S \\
\hline Agosto & I & I & $\mathrm{C}$ & $\mathrm{C}$ & $\mathrm{S}$ & S \\
\hline Setembro & I & I & C & C & S & S \\
\hline Outubro & I & $\mathrm{C}$ & $\mathrm{C}$ & S & S & S \\
\hline Novembro & I & C & C & S & S & S \\
\hline Dezembro & C & $\mathrm{C}$ & S & $\mathrm{S}$ & S & S \\
\hline
\end{tabular}

\section{Município de Bandeirantes}

TABELA 5 - Índice de Temperatura e Umidade (ITU) para o município de Bandeirantes Table 5 - Temperature and Humidity Index (ITU) for the municipality of Bandeirantes

\begin{tabular}{lc|c|c|c|c|c}
\hline \multirow{2}{*}{ Meses } & \multicolumn{6}{c}{ Idade em semanas de vida } \\
\cline { 2 - 7 } & $1^{\mathrm{a}}$ semana & $2^{\mathrm{a}}$ semana & $3^{\mathrm{a}}$ semana & $4^{\mathrm{a}}$ semana & $5^{\mathrm{a}}$ semana & $6^{\mathrm{a}}$ e $7^{\mathrm{a}}$ semanas \\
\hline Janeiro & $\mathrm{C}$ & $\mathrm{C}$ & $\mathrm{S}$ & $\mathrm{S}$ & $\mathrm{S}$ & $\mathrm{S}$ \\
Fevereiro & $\mathrm{C}$ & $\mathrm{C}$ & $\mathrm{S}$ & $\mathrm{S}$ & $\mathrm{S}$ & $\mathrm{S}$ \\
Março & $\mathrm{C}$ & $\mathrm{C}$ & $\mathrm{S}$ & $\mathrm{S}$ & $\mathrm{S}$ & $\mathrm{S}$ \\
Abril & $\mathrm{I}$ & $\mathrm{C}$ & $\mathrm{C}$ & $\mathrm{S}$ & $\mathrm{S}$ & $\mathrm{S}$ \\
Maio & $\mathrm{I}$ & $\mathrm{I}$ & $\mathrm{C}$ & $\mathrm{C}$ & $\mathrm{S}$ & $\mathrm{S}$ \\
Junho & $\mathrm{I}$ & $\mathrm{I}$ & $\mathrm{C}$ & $\mathrm{C}$ & $\mathrm{C}$ & $\mathrm{S}$ \\
Julho & $\mathrm{I}$ & $\mathrm{I}$ & $\mathrm{I}$ & $\mathrm{C}$ & $\mathrm{C}$ & $\mathrm{S}$ \\
Agosto & $\mathrm{I}$ & $\mathrm{I}$ & $\mathrm{C}$ & $\mathrm{C}$ & $\mathrm{S}$ & $\mathrm{S}$ \\
Setembro & $\mathrm{I}$ & $\mathrm{I}$ & $\mathrm{C}$ & $\mathrm{C}$ & $\mathrm{S}$ & $\mathrm{S}$ \\
Outubro & $\mathrm{I}$ & $\mathrm{C}$ & $\mathrm{C}$ & $\mathrm{S}$ & $\mathrm{S}$ & $\mathrm{S}$ \\
Novembro & $\mathrm{I}$ & $\mathrm{C}$ & $\mathrm{C}$ & $\mathrm{S}$ & $\mathrm{S}$ & $\mathrm{S}$ \\
Dezembro & $\mathrm{C}$ & $\mathrm{C}$ & $\mathrm{S}$ & $\mathrm{S}$ & $\mathrm{S}$ & $\mathrm{S}$ \\
\hline
\end{tabular}

Analisando as Tabelas do ITU (TABELAS 2 e 5) durante os meses de janeiro a dezembro, referente ao ciclo de vida de aves de corte, verifica-se que para a $1^{\mathrm{a}}$ semana de idade, o microclima apresenta valores inferiores durante os meses de abril a novembro, necessitando de um sistema de aquecimento para as aves neste período, o que não ocorre durante o restante do anos nesta fase de vida das aves; para a $2^{\mathrm{a}}$ semana de idade, pode-se verificar a mesma ocorrência, porém por um período menor, necessidade de aquecimento, agora, durante os meses de maio a setembro. Para a $3^{a}$ semana de idade, pode-se verificar que apenas durante 
o mês de julho existe a necessidade de aquecimento do microclima, porém durante os meses de dezembro a março tem-se o inverso, ou seja, necessidade de resfriamento do galpão, apresentando-se dentro dos limites de conforto térmico durante os meses restantes para essa fase de vida das aves. Para a $4^{\mathrm{a}}$ semana, verificase que o ITU apresenta-se dentro dos limites de conforto térmico para as aves durante os meses de maio a setembro, mas ultrapassam os valores superiores, necessitando de resfriamento do microclima de outubro a abril. Para a $5^{\text {a }}$ semana de idade, o ITU apresenta-se dentro de limites confortáveis, apenas durante 2 meses no ano (os meses junho e julho) já durante o restante do ano acima dos limites de conforto desejáveis para as aves nesta idade de vida. Para as $6^{\mathrm{a}}$ e $7^{\mathrm{a}}$ semanas de idade, pode-se verificar que o ITU apresenta valores superiores em praticamente todo o ano, gerando necessidade de resfriamento do microclima dentro do galpão, ou seja, os equipamentos de resfriamento da temperatura necessitam estar em funcionamento durante praticamente os 12 meses do ano, o que gera aumento nos custos de produção.

\section{CONCLUSÕES}

De acordo com os resultados obtidos nesta pesquisa, pode-se concluir que:

- as microrregiões analisadas não apresentaram condições para um ótimo desenvolvimento das aves, necessitando de investimentos em equipamentos que promovam a correção do microclima para estabelecer níveis ideais de conforto térmico para as aves;

- atenção especial deve ser dada à escolha do tipo de material de cobertura (telhas), pois essas podem piorar as condições de desconforto das aves durantes os meses mais quentes do ano;

- a localização do galpão também é de fundamental importância, pois ventos dominantes, orientação e radiação podem alterar as condições microclimáticas dos galpões;

- é necessária a realização de um estudo da viabilidade econômica, considerando as condições de conforto térmico para produção de aves.

\section{REFERÊNCIAS}

ABREU, V. M. N.; ABREU, P. G. Diagnóstico bioclimático para a produção de aves no Oeste paranaense. In: CONGRESSO BRASILEIRO DE ENGENHARIA AGRÍCOLA, 30., 2001, Foz do Iguaçu. Anais... Foz do Iguaçu: UNIOESTE/SBEA, 2001. 1 CD-ROM.

FERNANDES FILHO, J., F.; QUEIROZ, A. M. As Transformações Recentes na Base Técnica da Avicultura de Corte Brasileira. In: CONGRESSO DE CIÊNCIAS HUMANAS, LETRAS E ARTES, 5. 2001, Ouro Preto. Anais...Ouro Preto, MG: UFOP, 2001. p.1 v. 1.

GARCIA, L. A. F. Economias de escalas na produção de frangos de corte no Brasil. Piracicaba, 2004. 114 f. Tese (Doutorado Ciências) - Escola Superior de Agricultura “Luiz de Queiroz”, Universidade de São Paulo, 2004.

THOM, E. C. Cooling degree-days air conditioning, weating and ventilating. Translactions of the ASAE, Atlanta, v. 55, n. 7, p. 65-72, 1958.

TICÔNO, I. F. F., Ambiência e instalações para avicultura industrial. In: CONGRESSO BRASILEIRO DE ENGENHARIA AGRÍCOLA, 27., e Encontro Nacional de Técnicos, Pesquisadores e Educadores de Construções Rurais, 3., 1998, Poços de Caldas. Anais... Lavras: UFLA/SBEA, 1998. p. 1-86.

Recebido em: 27/03/2007

Received in: 03/27/2007

Aprovado em: 31/07/2007

Approved in: 07/31/2007

Rev. Acad., Curitiba, v. 5, n. 4, p. 385-390, out./dez. 2007 